\title{
Detecting and Mapping Root-Knot Nematode Infection in Coffee Crop Using Remote Sensing Measurements
}

\author{
George Deroco Martins ${ }^{(0)}$, Maria de Lourdes Bueno Trindade Galo, and Bruno Sergio Vieira
}

\begin{abstract}
Nematodes are a serious issue for coffee cultivation in Brazil. Because root infection by nematodes induces spectral variation in leaves and defines a unique spatial configuration in the cultivation field, the aim of this study was to use biophysical parameters and remote sensing data to discriminate and map healthy, moderately infected, and severely infected coffee plants. An experimental area in southern Minas Gerais State, in which the occurrence of nematodes was certified, was selected, and biophysical and spectral measurements of the leaves were made. Hyperspectral data were also used in a band simulation of the RapidEye sensor to identify the most sensitive spectral ranges for pathogen discrimination in coffee plants. These bands, plus a normalized difference vegetation index image, were used for a multispectral classification of healthy and nematode-infected areas. None of the biophysical parameters efficiently discriminated the leaves of healthy and infected plants, but the band simulation indicated that red, red edge, and near infrared spectral ranges were complementary to the discrimination of healthy coffee plants and the two levels of infection. The multispectral classification defined the spatial distribution of healthy, moderately infected, and severely infected coffee plants, with an overall accuracy of $78 \%$ and Kappa coefficient of 0.71 . Consideringthe degree of uncertainty and high cost involved in conventional detection of soil parasites, thelevels of accuracy achieved were adequate.
\end{abstract}

Index Terms-Coffee plantation, disease detection, mapping, nematodes, precision agriculture, remote sensing, spectral characterization.

\section{INTRODUCTION}

C OFFEE (Coffea spp.) is a heavily traded global commodity, surpassed only by crude oil. Its cultivation, processing, and commercialization support millions of direct and indirect jobs in urban and rural environments in many countries. Brazil is the largest producer and exporter of coffee in the world, and

Manuscript received October 13, 2016; revised June 15, 2017; accepted July 30, 2017. Date of publication August 23, 2017; date of current version December 19, 2017. (Corresponding author: George Deroco Martins.)

G. D. Martins is with the Graduate Program in Cartographic Science, São Paulo State University, Presidente Prudente, SP 19060-900, Brazil (e-mail: deroco@ufu.br).

M. de L. T. B Galo is with the Department of Cartography, São Paulo State University, Presidente Prudente, SP 19060-900, Brazil (e-mail: mlourdes@ fct. unesp.br).

B. S. Vieira is with the Institute of Agricultural Science, Federal University of Uberlândia, Monte Carmelo, MG 38500-000, Brazil (e-mail: brunovieira@ ufu.br).

Color versions of one or more of the figures in this paper are available online at http://ieeexplore.ieee.org.

Digital Object Identifier 10.1109/JSTARS.2017.2737618 the southern region of Minas Gerais State is responsible for approximately $30 \%$ of the national coffee production [1].

Nematodes are a major threat to the productivity of the coffee sector in Brazil and several species of many genera of nematodes have been found to be associated with the roots of coffee plants. In the southern region of Minas Gerais, diseases caused by rootknot nematodes (Meloidogyne spp.), especially Meloidogyne exigua, Meloidogyne paranaensis, and Meloidogyne incognita, are particularly harmful due to their destructive potential [2].

Traditionally, the diagnosis of extensive areas infested by nematodes and the determination of severity levels in these areas is expensive and not always technically feasible. An accurate estimation of damage potential requires the laboratory analysis of a large number of soil samples to estimate the most critical sites in an infested area. Losses caused by nematodes and the high cost of laboratory analysis of soil samples distributed over the whole acreage required for successful control of the dissemination of infection in coffee plantations involves the development of methods of the detection and quantification of site-specific damage.

Such conditions comply with the basic principle of precision agriculture: the presence, distribution, and intensity of a specific yield-reducing factor within a field must be identifiable [3] The costs of extensive sampling and a full area application of control measures can be improved by mapping the occurrence of nematodes through remote sensing.

Remote monitoring of vegetation stress responses is particularly important in precision agriculture and both "in field" sensors and airborne or satellite-based instruments have potential for such agricultural applications [4].

On the other hand, Hillnhütter et al. [3] report that the induction of symptoms in leaves, the clustered occurrence, and the low level of mobility in the soil make nematodes ideal targets for remote sensing detection and applications of precision agriculture. Several approaches have been evaluated for the detection of symptomatic and asymptomatic plant diseases by remote sensing based on spectroscopy [5]-[11] or multispectral and hyperspectral imaging [12]-[14].

Currently, a number of new spaceborne multispectral sensors with appropriate narrow spectral bands are in operation. Some have a chlorophyll-sensitive red edge band at $710 \mathrm{~nm}$ which has been shown to provide accurate information on the subtle variations in the structure and condition of vegetation [7]. Additionally, improvements in the normalized difference vegetation index (NDVI), calculated from NIR reflectance and red reflectance at or near $700 \mathrm{~nm}$, provided more accurate estimates of leaf chlorophyll concentration than for the traditional 
NDVI derived from NIR and red reflectance in the chlorophyll absorption trough between 660 and $680 \mathrm{~nm}$ [13].

Detecting and mapping pests and diseases in agricultural crops with remote sensing is usually based on changes in the spectral response of the plant due to impairment of their leaf structure. For root-knot nematodes, manifestation of damage in the aerial part of the plant is delayed and symptoms on leaves are similar to other types of plant stress. Considering these difficulties, we assumed that the low capacity of pathogen dispersal and its occurrence in clusters, forming small clearings along the planting rows, favors the definition of a spatial pattern best detected at smaller scales.

The purpose of this paper was therefore to discriminate and map the coffee area infected by nematodes in an experimental area located in the southern region of Minas Gerais State based on the spectral response of leaves registered in multispectral images. Our premise is that, due to the variation induced in the leaves and the spatial configuration of infection by nematodes, remote sensing is the best approach to monitor coffee crops for precision agriculture applications.

\section{Methodology}

To evaluate the hypothesis that remote sensing is the best approach to monitor root-knot nematodes in coffee crops, agronomical parameters such as leaf area index (LAI), chlorophyll relative content obtained by soil and plant development analyzer (SPAD), biomass measurements, and radiometric data were collected from plots of healthy and infected coffee plants. For the spectral characterization, radiometric data of leaves measured from the same plants used to estimate agronomical parameters enabled the identification of the most sensitive spectral ranges for discrimination of the infected coffee plots. This attribute selection was considered in the healthy and root-knot nematodeinfected area mapping, based on RapidEye multispectral image classification. The overall framework of the research is shown in Fig. 1.

\section{A. Experimental Area}

The experiment was performed on a coffee plantation located in the southeastern region of Brazil, Minas Gerais State in the municipality of Monte Carmelo [see Fig. 2(a)], in the largest coffee producing region of the country. The selected experimental area (centered in UTM: $253850 \mathrm{E}, 7916810 \mathrm{~N} / 23 \mathrm{~S}$, Reference System: WGS-84) consists of plots of coffee culture in advanced stage of development (approximately ten years), as shown in Fig. 2(b), in which the presence of root-knot nematodes of the genus Meloidogyne was certified.

In this study, the areas were classified into three categories according to the severity level of root-knot nematodes in coffee plants:

1) Healthy, with asymptomatic plants without the presence of nematodes;

2) Moderately infected, plants with mild reflex symptoms of root-knot nematodes; and

3) Severely infected, plants with advanced reflex symptoms of root-knot nematodes.

The diagnosis was made visually from the characteristic of reflex symptoms in plants induced by the nematodes, such as chlorotic leaves, defoliation, and undeveloped bushes, and con-

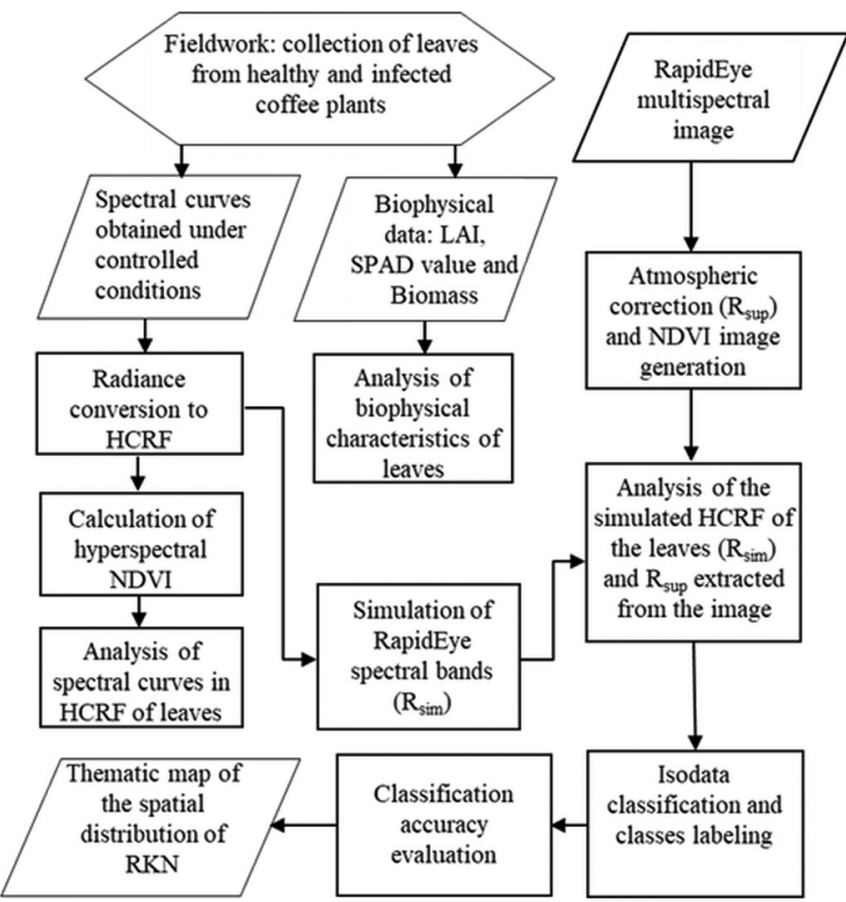

Fig. 1. Overall flowchart of methodology. LAI is Leaf Area Index. SPAD is Soil and Plant Development Analyzer. HCRF is Hemispheric Conical Reflectance Factor. NDVI is Normalized Difference Vegetation Index. $R_{\text {sim }}$ and $\mathrm{R}_{\text {sup }}$ are simulated reflectance (from HCRF) and surface reflectance extracted from the RapidEye image with atmospheric correction, respectively. RKN is Root-Knot Nematode.

firmed by nematological analysis of soil samples. Fig. 2(d) shows the characteristics of healthy and infected plants of the experimental area.

\section{B. Data Acquisition}

In a field campaign conducted in early November 2013, radiometric and biophysical data were acquired according to the sample design shown in Fig. 2(c). The sampling points indicated by circles in this figure represent the georeferenced position of the plants from which leaves were collected and used to perform radiometric and biophysical measurements.

Regarding the agronomic parameters, the LAI and chlorophyll relative content were measured by an AM300 Leaf Area Meter and SPAD-502 Chlorophyll Meter, respectively. For the biomass measurement, dry matter was weighed after a $48 \mathrm{~h}$ drying process at $65^{\circ} \mathrm{C}$ in a forced-circulation oven. For each sampling unit, ten replicates were measured, and the average value for the parameter was obtained.

For radiometric measurements, leaves were collected from the four cardinal points of the basal third region of the plant to compensate for variation in light conditions. Each leaf identified as coming from a healthy, moderately, or severely infected plant was placed on a black cloth and the measurements were taken in an environment with controlled artificial lighting, using a similar approach to [15]. An ASD FieldSpec HandHeld spectroradiometer, operating in the spectral range of $375-1075 \mathrm{~nm}$, set on 512 channels with $1.6 \mathrm{~nm}$ spectral resolution and an FOV of $1^{\circ}$, was used to measure leaf radiance. Ten spectra for each leaf were collected to minimize noise and the averages were used. For each measurement of leaf radiance, the radiance of a 


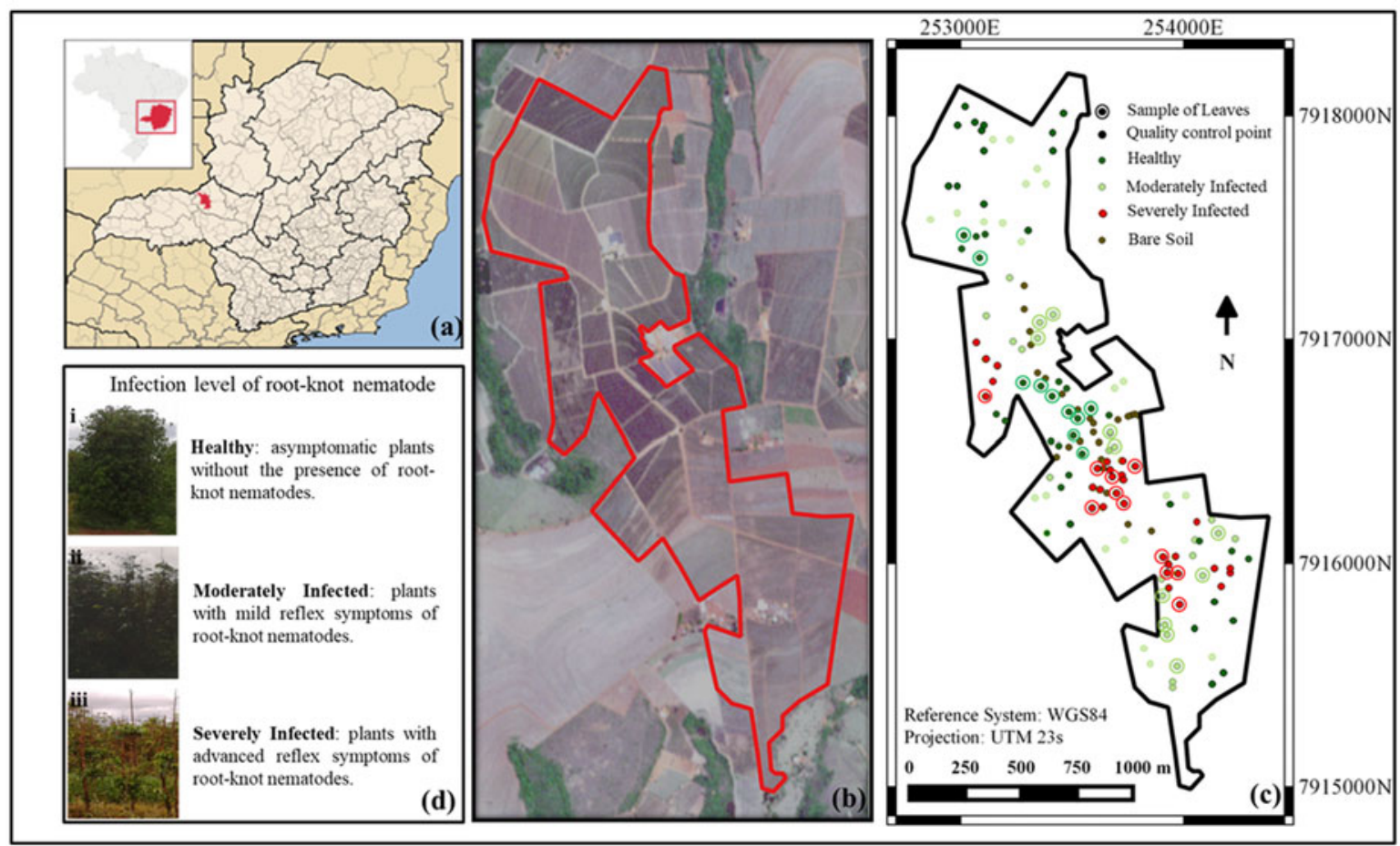

Fig. 2. (a) Characterization of the experimental area. Monte Carmelo municipality highlighted in the Minas Gerais State and Brazil maps. (b) RGB natural color composition of the RapidEye image with study area bordered in red. (c) Spatial distribution of georeferenced sample points: circles represent the location of plants from which the leaves were collected to perform biophysical and radiometric measurements; points indicate sampling elements for the accuracy evaluation. (d) Aspects of plants under different levels of infection by root-knots nematodes.

Lambertian reference surface (Spectralon plate) was also measured under the same conditions of illumination and observation to estimate the Hemispheric Conical Reflectance Factor (HCRF) of the leaf. The target was illuminated by two collimated artificial light sources (halogen lamp of Quartz-Tungsten) oriented $120^{\circ}$ from the Zenith and positioned $1 \mathrm{~m}$ above the target of interest in the acquisition of these measurements.

The HCRF is defined as the ratio between the target's radiant flux and the flow that would be reflected by a Lambertian surface without loss by absorption and transmission considering the same geometry of light conditions and target [16]-[17]. In a controlled environment, such as in a laboratory, HCRF is defined by

$$
\operatorname{HCRF}\left(\omega_{i} \omega_{r}\right)=\frac{d L\left(\theta_{r}, \Phi_{r}\right)(\text { target })}{d L\left(\theta_{r}, \Phi_{r}\right) \text { (reference) }} K\left(\theta_{i}, \Phi_{i}, \theta_{r}, \Phi_{r}\right)
$$

where $d L$ is the radiance (target or Lambertian plate), $\omega$ is the solid angle, $\theta$ and $\Phi$ are the zenith and azimuth angles, respectively, $i$ is associated with the incident flux, and $r$ with the reflected flux. $K$ is the correction factor that considers the calibration coefficient specified by the spectral reflectance of the reference panel.

The average of ten measurements per leaf and the plate correction factor $(K)$ were used for the transformation of radiance in HCRF. Thus, a spectrum was produced for each sample element.

The multispectral image used to map healthy coffee and root-knot nematode-infected areas was acquired by the RapidEye satellite constellation on October 13, 2013 and was obtained from the satellite image catalog of the Ministry of Environment, accessible to Brazilian public institutions (http:// geocatalogo.mma.gov.br). RapidEye imaging has five spectral bands (blue: $440-510 \mathrm{~nm}$, green: $520-590 \mathrm{~nm}$, red: $630-685$ $\mathrm{nm}$, red edge: $690-730 \mathrm{~nm}$, and near infrared: $760-850 \mathrm{~nm}$ ) and 12-bit radiometric resolution. It is available with $6.5 \mathrm{~m}$ of ground sampling distance orthorectified to $5 \mathrm{~m}$ and a basic level of geometric and radiometric correction, including adjustment to a WGS84 reference system and radiometric calibration of the spectral bands.

There is a time lag of approximately 20 days between the image acquisition and leaf sample collection in the field. In this study, however, this period of time does not influence the data integration because coffee is a perennial crop that maintains its biophysical characteristics throughout the same season.

\section{Data Processing}

Diagrams showing the LAI values, chlorophyll content, and biomass were used to differentiate healthy coffee plants and plants subjected to different levels of infection by root-knot nematodes based on biophysical parameters.

Regarding the radiometric data, HCRF curves were used to show the spectral response of leaves collected from healthy and infected coffee plants. In addition, the HCRF values were used in the band simulation of the RapidEye sensor to initially select suitable spectral ranges for separation between the levels of infection. To simulate the HCRF corresponding with the values recorded by the RapidEye sensor for each band centered at wavelength $\lambda_{i}$, the spectral response function (SRF) for RapidEye bands [18] was used, as defined by [19], shown in

$$
R_{\mathrm{SIM}}\left(\lambda_{i}\right)=\frac{\sum_{\lambda} \operatorname{HCRF}(\lambda) * \operatorname{SRF}(\lambda)}{\sum_{\lambda} \operatorname{SRF}(\lambda)}
$$


where $R_{\mathrm{SIM}}\left(\lambda_{i}\right)$ is the simulated reflectance (from HCRF) at the wavelength of band $\lambda_{i}$, and $\operatorname{SRF}(\lambda)$ is the RapidEye SRF. The hyperspectral intervals considered for band simulation were the same as the RapidEye spectral bands: 440-510 nm (blue); 520-590 nm (green); 630-685 nm (red); 690-730 nm (red edge); $760-850 \mathrm{~nm}$ (near infrared).

In addition to the original spectral bands, the potential for discrimination by levels of infection was assessed by the NDVI [20]. This metric is typically used to infer the biophysical characteristics of vegetation, including phytosanitary conditions [21]-[22]. The NDVI is expressed by the normalized ratio, as given in the following:

$$
\mathrm{NDVI}=\left[\frac{R_{\mathrm{SIM}}(\text { near infrared })-R_{\mathrm{SIM}}(\mathrm{red})}{R_{\mathrm{SIM}}(\text { near infrared })+R_{\mathrm{SIM}}(\mathrm{red})}\right] .
$$

\section{Multispectral Image Analysis}

The processing of the RapidEye multispectral image consisted of atmospheric scene correction, the generation of an NDVI image, and the application of an unsupervised classification method to aggregate pixels with similar radiometric attributes, enabling the later association of groups formed with the classes of information of interest (healthy coffee, moderately infected, severely infected and bare soil).

Atmospheric correction was required because the RapidEye image did not include treatment to minimize the effects of atmospheric absorption and electromagnetic radiation scattering. The correction was performed using environment for visualizing images software, using the fast line-of-sight atmospheric analysis of hypercubes (FLAASH) correction method [23]. FLAASH is based on a radiative transfer model and considers that the radiance detected by the sensor is a function of the pixel reflectance and its surroundings, the downward hemispherical albedo, the path radiance, transmittance, and acquisition geometry [24]. It is based on MODerate resolution atmosphere TRANsmittance (MODTRAN4) code, which requires the prior definition of the aerosol model, geographic location, elevation, satellite altitude, date and time of acquisition, and other atmospheric parameters (such as the $\mathrm{CO}_{2}$ concentration).

Some of the parameters required by FLAASH were extracted from the RapidEye image metadata file. The concentration of water vapor was derived from the MOD07-L2 MODIS/Terra product, whose acquisition was coincident with the image. The specification of the aerosol model (tropical) and other variables followed the recommendations of [25] and [23].

The pixel attributes of the atmospheric-corrected image represent the surface reflectance $\left(\mathrm{R}_{\mathrm{SUP}}\right)$. Thus, $\mathrm{R}_{\mathrm{SUP}}$ was extracted from each spectral band of the RapidEye image in the same position as the georeferenced sample elements and related with the simulated reflectance $\left(\mathrm{R}_{\mathrm{SIM}}\right.$ - obtained from HCRF) for these bands, as well as NDVI [also generated using $R_{S U P}$ in (3)], through diagrams showing the reflectance variability for healthy and infected coffee. Those graphs, along with the mean and standard deviation values, allowed verification of the capacity of discrimination of the spectral bands and NDVI and identified the most suitable input data for classification. In this case, NDVI is expressed by the normalized ratio shown in

$$
\mathrm{NDVI}=\left[\frac{R_{\mathrm{SUP}}(\text { near infrared })-R_{\mathrm{SUP}}(\mathrm{red})}{R_{\mathrm{SUP}}(\text { near infrared })+R_{\mathrm{SUP}}(\mathrm{red})}\right] .
$$

The classification was performed using the unsupervised iterative self-organizing data analysis algorithm, which consists of clustering pixel vectors with spectral similarity using minimum distance techniques. A change threshold of $10 \%$ was adopted to end the iterative process.

The clusters formed at sites where healthy and infected coffee leaves were collected [see Fig. 2(c)] were directly associated with information classes representing healthy, moderately, or severely infected coffee. The assignment of classes to the remaining clusters was based on visual perception of reflex symptoms indicative of the occurrence of nematodes in greater or lesser density. The bare soil class definition only considered the differentiated spectral response of this type of land cover.

To assess the reliability of the map of areas infected by rootknot nematodes, the classification accuracy was evaluated by confusion matrix, Kappa statistical coefficient, and producer's and user's accuracy by class [26]. The geographical position and ground truth of 145 sample points were considered for this analysis, whose spatial distribution in the study area is shown in Fig. 2(c).

\section{RESULTS AND DISCUSSION}

\section{A. Biophysical Characterization of Leaves: Healthy and Parasitized by Root-Knot Nematodes}

Changes in LAI, biomass, and chlorophyll content are characteristic of several types of stress in vegetation [27]. To determine whether these biophysical indices can discriminate leaves from healthy and infected coffee plants, the average values obtained from ten replicates of each sample are shown in the graphs of the SPAD index reading, LAI, and biomass (see Fig. 3).

For the three indices, there is perceptible variability in the values measured for the same phytosanitary conditions, especially healthy coffee plants and early infected plants. The variation among the phytosanitary conditions, however, is not as noticeable, despite the subtle decrease between measurements obtained on healthy and severely infected coffee plants. This behavior, which is observed in the LAI [see Fig. 3(b)] and biomass [see Fig. 3(c)] graphics, is confirmed by the decrease in their averages. The SPAD readings resulted in the most homogeneous measures among the three conditions and evaluated indices.

The negative correlation between some biophysical parameters, particularly LAI and biomass, and coffee plants infected with knot-root nematodes and other parasites, agrees with previous reports [27]. However, even with the indication of subtle differences among the three conditions of coffee plants evaluated, none of the agronomic parameters efficiently discriminated samples of healthy and moderately infected coffee plants.

\section{B. Spectral Characterization of Leaves: Healthy and Parasitized by Root-Knot Nematodes}

Fig. 4 shows the HCRF curves obtained for each sample [see Fig. 4(a)] and the mean curves for each of the three phytosanitary conditions [see Fig. 4(b)]. The curves, regardless of being generated from measurements in healthy, moderately, or severely infected coffee plants, show typical characteristic absorption features and scattering reflectance of the vegetation with noticeable variation in magnitude in the visible and near infrared wavelength regions. 

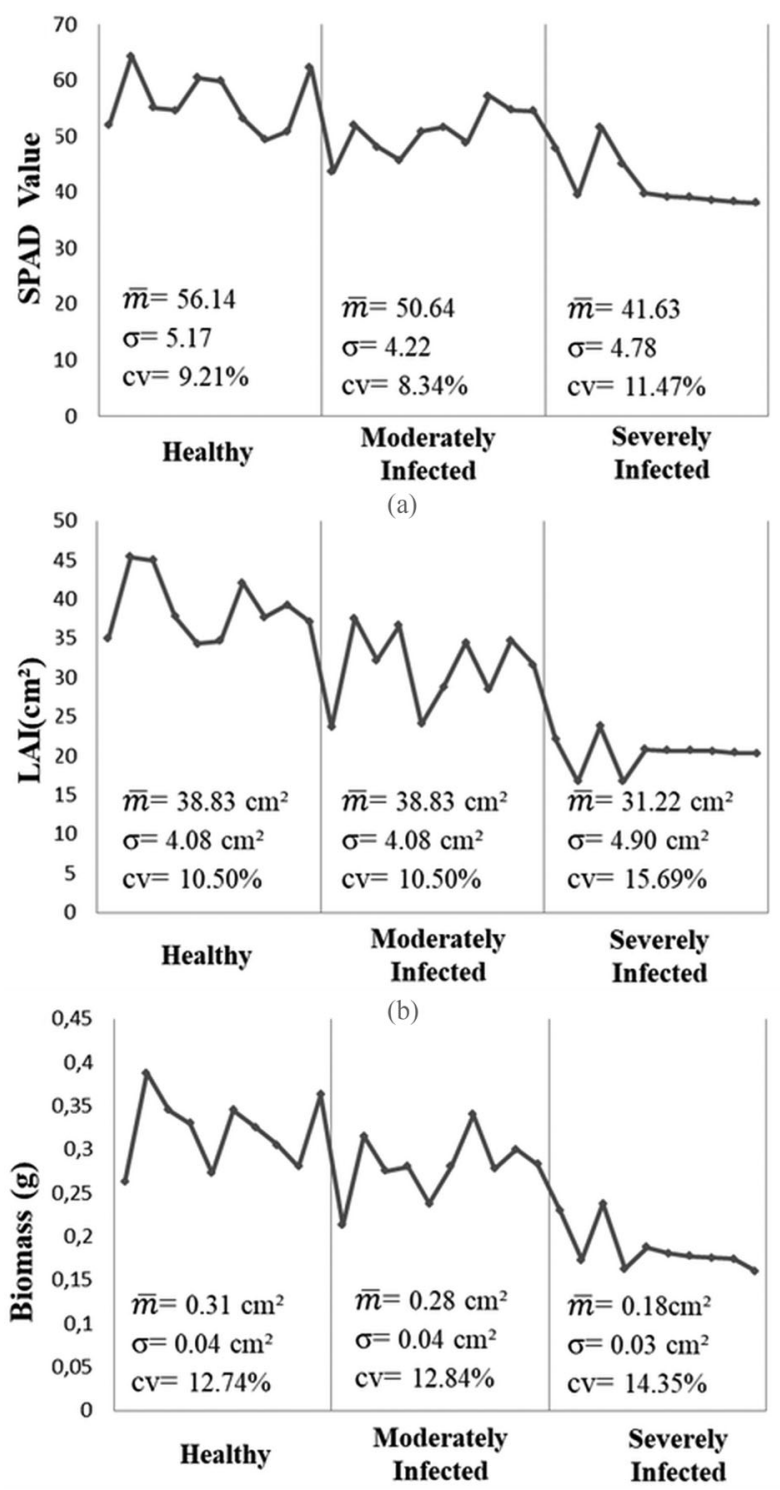

(c)

Fig. 3. Biophysical indicator variability recorded for leaves of healthy, moderately infected, and severely infected coffee plants. (a) SPAD index readings. (b) LAI in $\mathrm{cm}^{2}$. (c) Biomass content in grams. For each plant condition, $\bar{m}$ is the sample mean, $\mathrm{SD}$ is the standard deviation, and $\mathrm{CV}$ is the variation coefficient.

The overall shape of the curves in the visible spectrum indicates that healthy and moderately infected coffee plants have classical absorption bands of chlorophyll. These absorptions are discernible even in severely infected leaves, but this condition is characterized by subtly greater HCRF average values in the visible spectrum, particularly between 550 and $680 \mathrm{~nm}$. This spectral behavior is consistent with an advanced level of infection of the culture due to changes in the structure of the leaves, which become chlorotic and yellowish [28]. Symptoms such as yellowing and wilting of leaves are the basis for detection by remote sensing of this type of disease and are identified by increased spectral response in the red wavelength region (between approximately 620 and $720 \mathrm{~nm}$ ).

In the near infrared region $(720-1000 \mathrm{~nm})$, there is a noticeable difference in the reflectance intensity of the leaves of

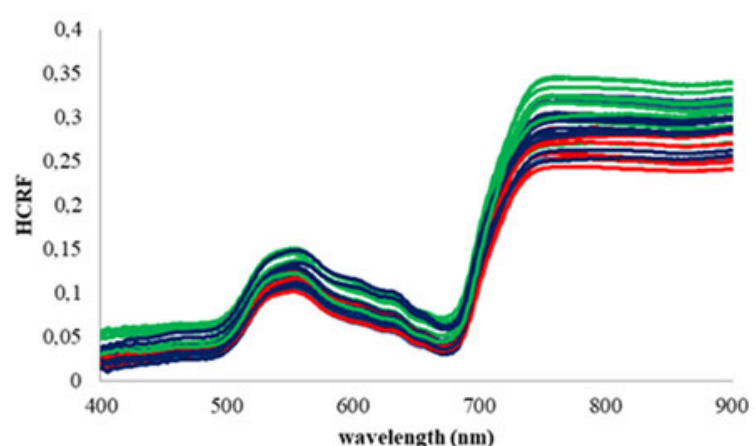

(a)

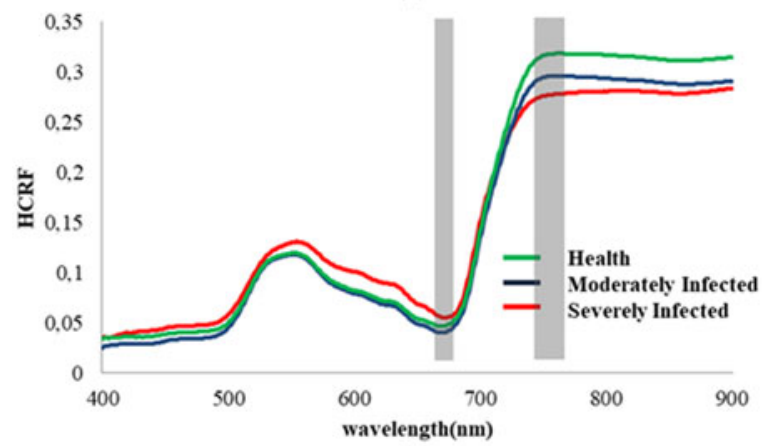

(b)

Fig. 4. HCRF curves obtained from healthy coffee leaves (shown in green), moderately infected (blue), and severely infected (red): (a) the whole sample and, (b) mean curves obtained for each condition, with gray-shaded strips indicating the most discriminant wavelength intervals.

healthy plants and severely infected plants. The greatest discrepancy is discernible in the wavelengths between 750 and $900 \mathrm{~nm}$. However, near $900 \mathrm{~nm}$, the difference in the spectral response of moderately and severely infected coffee plants starts to decrease gradually. As in [29], which used hyperspectral data for pathogen detection in tomato, the most suitable spectral region for discriminating healthy and infected plants was near infrared because plants under stress undergo changes in the internal structure of the leaf.

The spectral curve obtained from the leaves of coffee plants severely infected with knot-root nematodes showed the characteristic pattern of plants under stress, which is diagnosed by changes in the mechanisms of absorption and scattering of incident electromagnetic radiation in the visible (red) and near infrared regions [3], [27], [30], resulting from the decrease in chlorophyll content and alterations in the internal structure of the leaves [15].

\section{Discrimination of Healthy and Infected Coffee Plants by Simulated Data and RapidEye Spectral Bands}

Specifying RapidEye bands that best capture the subtle differences in the spectral response of healthy plants and plants infected with root-knot nematodes provides ensures that the leaf measurements and data extracted from the image are spectrally compatible. Thus, the RapidEye spectral bands were simulated from the HCRF measured of the leaves, and the image data were subjected to atmospheric correction to produce the simulated reflectance values $\left(\mathrm{R}_{\mathrm{SIM}}\right)$ and surface reflectance $\left(\mathrm{R}_{\mathrm{SUP}}\right)$. Fig. 5 shows the variation in the simulated HCRF values and 
Blue

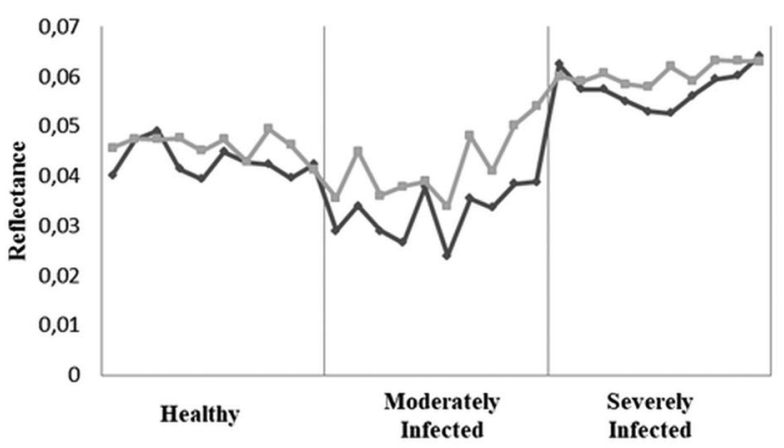

(a)

Red

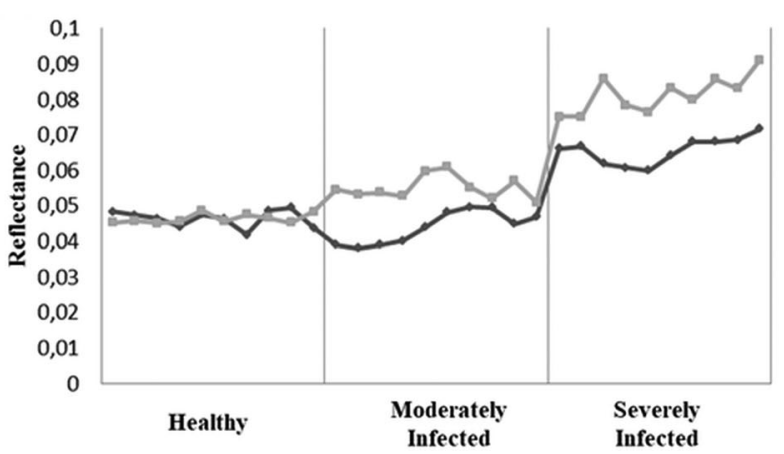

(c)

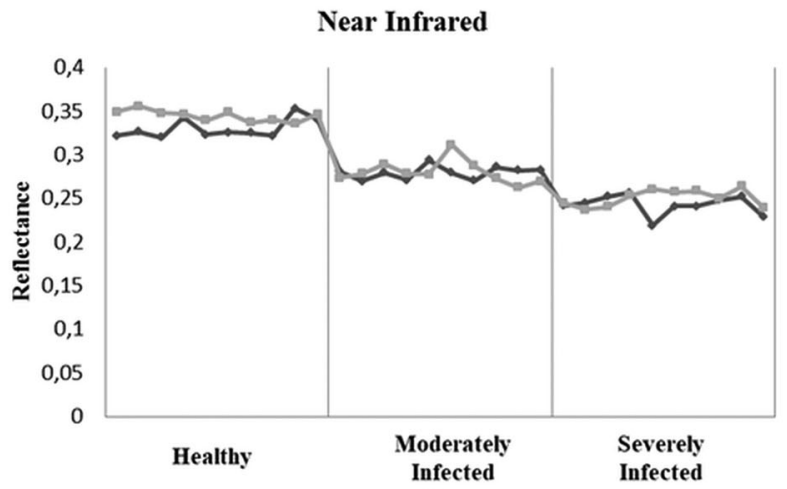

(e)

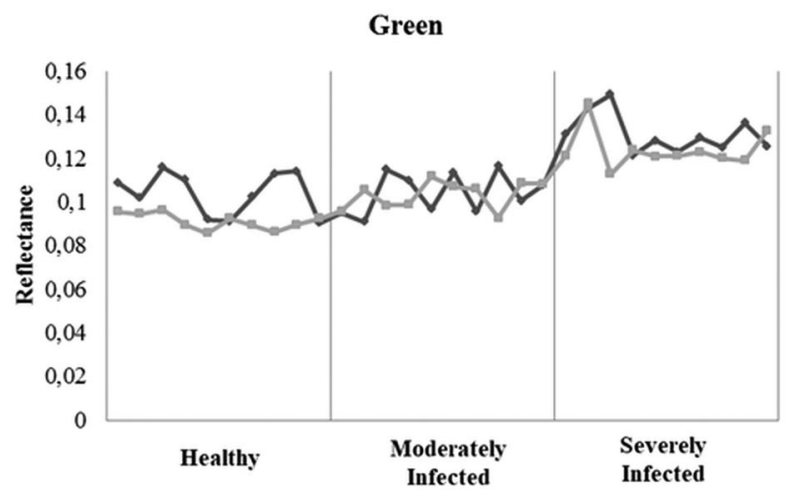

(b)

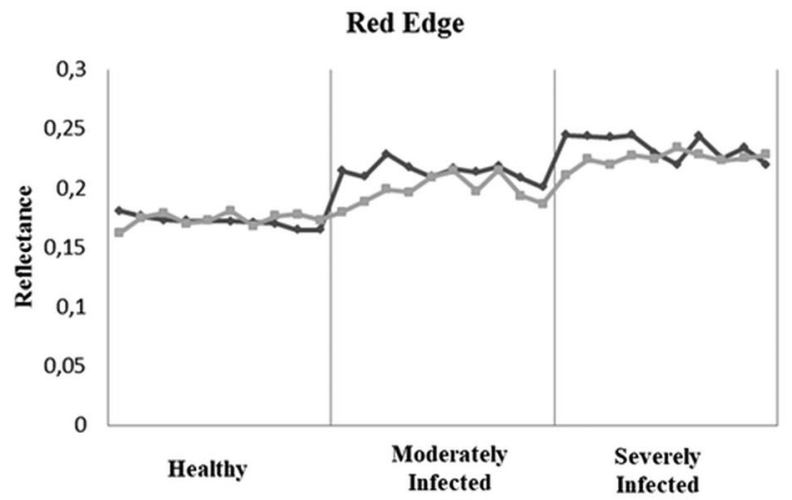

(d)

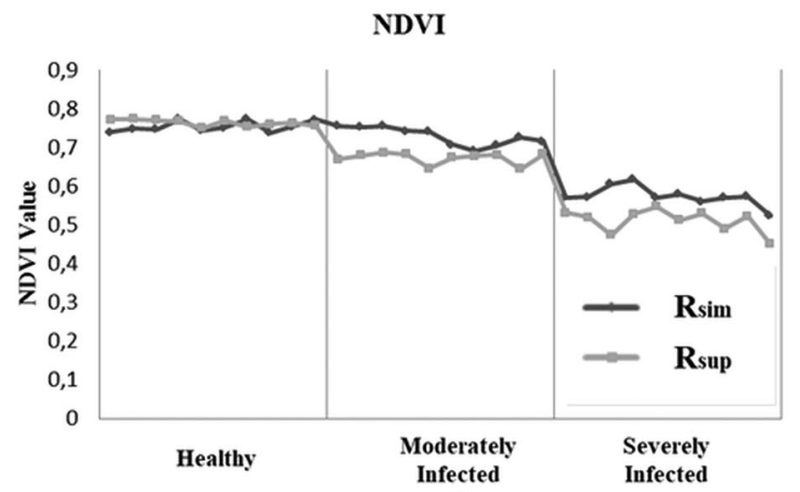

(f)

Fig. 5. Simulated HCRF $\left(R_{\text {SIM }}\right)$ and surface reflectance $\left(R_{\text {SUP }}\right)$ obtained from the spectral bands of the RapidEye image. (a) Blue: $440-510 \mathrm{~nm}$, (b) green: 520-590 nm, (c) red: 630-685 nm, (d) red edge: 690-730 nm, (e) near infrared: 760-850 nm, and (f) NDVI values.

surface reflectance extracted from the corresponding pixels in each RapidEye band.

The graphs in Fig. 4 show similar behavior between the HCFR simulated values $\left(\mathrm{R}_{\mathrm{SIM}}\right)$ and the surface reflectance $\left(\mathrm{R}_{\mathrm{SUP}}\right)$ obtained directly from the atmospherically corrected multispectral image. This perception is more evident in the red edge [see Fig. 5(d)] and near infrared [see Fig. 5(e)] spectral bands. The blue [see Fig. 5(a)] and green [see Fig. 5(b)] bands present higher variability in the simulated HCRF, which is slightly smoothed in the surface reflectance values, but the minor discrepancy in these reflectance values hinders the separation between healthy and infected coffee plants. The red spectral range [see Fig. 5(c)], however, shows a more pronounced discrepancy and a clear increase in the reflectance amplitude of severely in- fected coffee plants, especially in the values extracted from the image.

The suitability of the visible spectrum for detecting diseases in agricultural crops, such as leaf rust, is recurrent in remote sensing [30]. In the case of root parasites, such as nematodes, discrimination in the visible wavelengths occurs when the leaves start to show chlorotic characteristics.

The red edge and near infrared spectral bands have been identified as ideal for the discrimination of insects [31] and other pathogens in crops [30]. However, major discrepancies among the calculated mean reflectance of healthy, moderately infected, and severely infected coffee plants $\left(R_{\text {SIM }}\right.$ and $\left.R_{S U P}\right)$ were observed in the red and near infrared spectral ranges, as well as in the NDVI metrics. To summarize these remarks, 
TABLE I

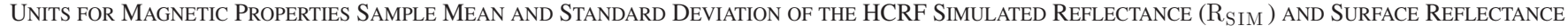
$\left(\mathrm{R}_{\mathrm{S} U \mathrm{P}}\right)$ OF HEALTHY AND INFECTED COFFEE PLANTS

\begin{tabular}{|c|c|c|c|c|c|c|c|}
\hline \multirow[t]{2}{*}{ Spectral region/NDVI } & \multirow[t]{2}{*}{ Statistic } & \multicolumn{2}{|c|}{ Healthy } & \multicolumn{2}{|c|}{ Moderately infected } & \multicolumn{2}{|c|}{ Severely infected } \\
\hline & & $\mathrm{R}_{\mathrm{SIM}}(\mathrm{HCRF})$ & $\mathrm{R}_{\mathrm{SUP}}$ (Image) & $\mathrm{R}_{\text {SIM }}(\mathrm{HCRF})$ & $\mathrm{R}_{\text {SUP }}$ (Image) & $\mathrm{R}_{\mathrm{SIM}}(\mathrm{HCRF})$ & $\mathrm{R}_{\mathrm{SUP}}$ (Image) \\
\hline \multirow[t]{2}{*}{ Blue (a) } & $\bar{m}$ & 0.042 & 0.046 & 0.032 & 0.042 & 0.057 & 0.060 \\
\hline & $s$ & 0.003 & 0.002 & 0.005 & 0.007 & 0.004 & 0.002 \\
\hline \multirow[t]{2}{*}{ Green (b) } & $\bar{m}$ & 0.104 & 0.091 & 0.104 & 0.103 & 0.131 & 0.124 \\
\hline & $s$ & 0.010 & 0.004 & 0.009 & 0.006 & 0.009 & 0.009 \\
\hline \multirow[t]{2}{*}{$\operatorname{Red}(\mathrm{c})$} & $\bar{m}$ & 0.046 & 0.046 & 0.044 & 0.054 & 0.065 & 0.081 \\
\hline & $s$ & 0.002 & 0.001 & 0.004 & 0.003 & 0.003 & 0.005 \\
\hline \multirow[t]{2}{*}{ Red Edge (d) } & $\bar{m}$ & 0.171 & 0.173 & 0.213 & 0.198 & 0.235 & 0.224 \\
\hline & $s$ & 0.005 & 0.006 & 0.007 & 0.012 & 0.010 & 0.006 \\
\hline \multirow[t]{2}{*}{ NIR (e) } & $\bar{m}$ & 0.330 & 0.344 & 0.279 & 0.280 & 0.242 & 0.250 \\
\hline & s & 0.011 & 0.006 & 0.007 & 0.013 & 0.011 & 0.009 \\
\hline \multirow[t]{2}{*}{ NDVI (f) } & $\bar{m}$ & 0.754 & 0.763 & 0.729 & 0.672 & 0.574 & 0.510 \\
\hline & s & 0.013 & 0.008 & 0.023 & 0.015 & 0.025 & 0.029 \\
\hline
\end{tabular}

$\mathrm{R}_{\mathrm{SIM}}$ : simulated HCRF; $\mathrm{R}_{\mathrm{S} U \mathrm{P}}$ : surface reflectance extracted from the corrected image; $\bar{m}$ : sample mean; $s$ : sample standard deviation; A, B, C, D, E, F: designation of the spectral regions coinciding with the RapidEye bands.

Table I presents the mean and standard deviation calculated from the sample elements of healthy, moderately infected, and severely infected coffee plants for the spectral ranges of the RapidEye original bands and the NDVI metric.

The greatest discrepancies in healthy and infected coffee plants occur in the mean of the red [see Fig. 5(c)] and infrared [see Fig. 5(e)] spectral regions, with different ratios but consistent with the pattern observed in the reflectance curves. The means of $R_{\text {SIM }}$ and $R_{\text {SUP }}$ calculated for severely and early infected coffee plants are different in the red spectral range [see Fig. 5(c)], with a higher average in the spectral response. At the leaf level, the higher simulated response is due to the change in photosynthetic activity. The surface reflectance extracted from the image includes the spectral response of bare soil, which is higher in this range [see Fig. (c)]. The difference in the level of acquisition of measurements is also responsible for the highest mean surface reflectance $\left(R_{\text {SUP }}\right)$ captured by an orbital sensor in relation to the simulated spectral response $\left(\mathrm{R}_{\mathrm{SIM}}\right)$ for this band.

In the near infrared region [see Fig. 5(e)], healthy vegetation has a higher reflectance average than early and severely infected coffee plants. In the red edge [see Fig. 5(d)], although $R_{\text {SUP }}$ has a high standard deviation, the average values of both $R_{\text {SIM }}$ as $R_{\mathrm{SUP}}$ for coffee plants in the early stages of infection are slightly different from the two other conditions, which only occurs in this spectral range.

The red, red edge, and near infrared spectral intervals were complementary for the discrimination of healthy coffee plants and the two infection levels [see Fig. 5 and Table I). NDVI showed the highest differences between early and severely infected coffee, especially for data extracted from the RapidEye image $\left(R_{S U P}\right)$.

\section{Spatial Distribution of Nematodes in the Study Area}

The thematic map produced by unsupervised classification and subsequent cluster labeling of healthy, moderately, and severely infected coffee plants, as well as bare soil, is shown in Fig. 5.

The distribution of moderately infected coffee plants extends throughout almost the entire study area, except in two central
TABLE II

CONFUSION MATRIX AND OMISSION AND COMMISSION ERRORS OF THE CLASSIFICATION

\begin{tabular}{lcccccc}
\hline \hline $\begin{array}{l}\text { Ground Truth } \\
\text { Classification }\end{array}$ & Healthy & $\begin{array}{c}\text { Moderately } \\
\text { Infected }\end{array}$ & $\begin{array}{c}\text { Severely } \\
\text { Infected }\end{array}$ & $\begin{array}{c}\text { Bare } \\
\text { soil }\end{array}$ & $\begin{array}{c}\text { Total } \\
\text { Commission } \\
\text { error (\%) }\end{array}$ \\
\hline Healthy & 41 & 5 & 1 & 0 & $\mathbf{4 7}$ & 12.76 \\
Moderately & 4 & 33 & 5 & 0 & $\mathbf{4 2}$ & 21.43 \\
Severely Infected & 0 & 7 & 15 & 0 & $\mathbf{2 2}$ & 31.82 \\
Bare soil & 0 & 0 & 9 & 25 & $\mathbf{3 4}$ & 26.47 \\
Total & $\mathbf{4 5}$ & $\mathbf{4 5}$ & $\mathbf{3 0}$ & $\mathbf{2 5}$ & $\mathbf{1 4 5}$ & \\
Omission error (\%) & 8.89 & 26.67 & 50 & 0 & & \\
\hline \hline
\end{tabular}

The overall accuracy of classification was $78.62 \%$, and the overall Kappa coefficient was 0.71 .

stands. The characteristic pattern of small clearings along the planting rows, associated with agricultural crops installed in areas infected by nematodes [32], is not always observed in this class.

The distribution of severely infected coffee plants in the study area is less extensive and is concentrated in the northeastern portion of the study area. Coffee plants severely infected by rootknot nematodes show a significant reduction in leaf area similar to the plant response to other environmental stress, such as drought, nutrient deficiency, salinity and other biotic stresses [4]. Further evidence of the similar plant response to various stresses and severe infection by nematodes is the extensive presence of bare soil following the death of plants and the formation of small clearings in the middle of the coffee fields.

Table II shows the spatial coincidence obtained by comparing 145 georeferenced sample points observed in situ [see Fig. 2(c)] and the labeling of healthy, moderately infected, and severely infected coffee plants and bare soil, indicated in the thematic map of Fig. 6. In the error matrix, the lines represent the elements assigned to classes in the classification process and the columns refer to the ground truth. The last line shows the omission errors by class (representing the producer's accuracy), and the last column shows the commission errors (representing the user's accuracy).

The classification results were compared with the georeferenced points checked in the field [see Fig. 2(c)], resulting in an 


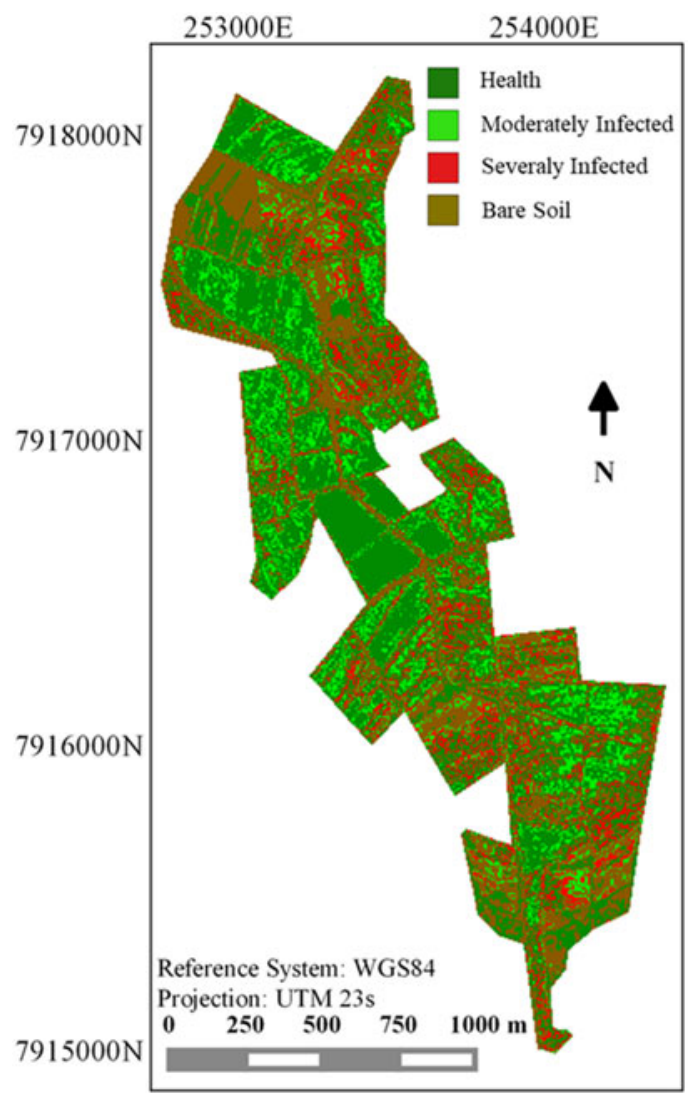

Fig. 6. Spatial distribution of healthy, moderately, and severely infected coffee plants in the study area obtained by unsupervised classification of the NDVI image and red, red edge, and near infrared RapidEye spectral bands.

overall accuracy of $78.62 \%$ and Kappa index of 0.71 and indicating a reasonable degree of accuracy. The producer's accuracy of the severely infected coffee class (50\%) was the most critical result because this class included several checkpoints in bare soil $(30 \%)$ and the moderate infection $(16.67 \%)$ classes. Confusion with bare soil is a natural consequence of very high levels of infection, which usually lead to plant death and the appearance of clearings without vegetation in the middle of the coffee plantation. Thereby, the probability that specific sample points fall in these clearings without vegetation is increased. The moderately infection coffee class (producer's accuracy equal to $73.33 \%$ ) was commonly confused with healthy coffee plants, resulting in an omission error of $26.67 \%$ and confirming the intermediate nature of this class. The healthy coffee plant and bare soil classes resulted in high producer's accuracy, respectively, $91.11 \%$ and $100 \%$.

The user's accuracy for the healthy coffee class was greater than $87 \%$, and the commission error $(12.76 \%$ ) mainly resulted from the inclusion of sample elements of the early infection coffee class. The greatest errors were caused by confusion between neighboring classes (severely and moderately infected coffee), which is expected in classification.

Considering the high cost and degree of uncertainty of the conventional detection of soil parasites, an indication of the spatial distribution of the areas infected by root-knot nematodes is relevant information in the context of precision agriculture. Furthermore, for a perennial crop, such as coffee, and a parasite of low mobility in soil, whose management does not require punctual intervention in infected plants, the level of accuracy achieved was adequate.

\section{CONCLUSION}

A key aspect in precision agriculture related to the monitoring of the phytosanitary conditions of plants and specific management is the mapping of the spatial distribution of agricultural areas infected by pests and parasites. In the case of root-knot nematodes, the delineation of the infected area is hindered by the late manifestation of symptoms in the aerial part of the plant.

Since root damage becomes visible in the foliage at different stages of plant development, the use of biophysical indices, such as LAI, biomass content, and SPAD, did not enable differentiation of healthy and infected coffee plants. Hyperspectral measurements performed on the same leaves assessed by biophysical indices indicated the viability of discriminating healthy coffee plants and the two levels of infection (initial and severely infected) in the near infrared spectral region because this spectral range is sensitive to changes in the internal structure of the leaf. As we expanded the spectral range of the hyperspectral data to simulate the bands of the RapidEye multispectral sensor, discrepancies in the wavelength intervals of the visible spectrum were able to differentiate the three conditions, and the most discriminating bands were selected for image classification.

Thus, classification using the red, red edge and near infrared bands, and NDVI image defined the spatial distribution of healthy, moderately infected, and severely infected coffee plants with an overall accuracy of 78\% and kappa coefficient of 0.71 . Although such classification performance does not appear promising, high confusion among severely infected coffee plants and bare soil, represented by a producer's accuracy of $50 \%$, can be explained by clearings formed inside the coffee fields as a result of the death of plants subjected to the drastic action of nematodes. The second largest source of error occurred between moderately and severe infection, whose transition is not well defined because it is related to the intensity of the symptoms manifested in plants.

The largest errors in classification were due to the natural development of an infected crop and the specific characteristics of infection by root-knot nematodes, such as the occurrence of clustering in the crop field and the low level of mobility of nematodes in soil. In this sense, the methodology applied to the study area enabled the mapping of infected areas and proved to be more effective for the detection of the parasite than the biophysical measures of the plant or even the punctual acquisition of hyperspectral data.

In addition, for a perennial crop, such as coffee, and a pathogen of low mobility in the soil, such as nematodes, whose management consists primarily of preventing their multiplication and the spread of infected soil to other plots of the plantation, mapping infected areas is an essential component of control in the context of precision farming.

\section{ACKNOWLEDGMENT}

The authors would like to thank the staff of the Regional Cooperative of Coffee Producers for help in identifying the experimental area used in this study and the Ministry of Environment of Brazil for providing the RapidEye image. 


\section{REFERENCES}

[1] D. H. Barbosa, R. M. Souza, and H. D. Vieira, "Field assessment of coffee (Coffea arabica L.) cultivars in meloidogyne exigua-infested or free fields in Rio De Janeiro State, Brazil," Crop Protection, vol. 29, no. 2, pp. 175177, Feb. 2010.

[2] A. F. Barros et al., "Root-knot nematodes, a growing problem for Conilon coffee in Espírito Santo State, Brazil," Crop Protection, vol. 55, no. 1, pp. 74-79, Jan. 2014.

[3] C. Hillnhütter et al., "Use of imaging spectroscopy to discriminate symptoms caused by heterodera schachtii and rhizoctonia solani on sugar beet," Precision Agriculture, vol. 13, no. 1, pp. 17-32, Jun. 2011.

[4] G. J. Hamlyn and R. Vaughan, Remote Sensing of Vegetation. Oxford, U.K.: Oxford Univ. Press, 2010, p. 284.

[5] L. G. Marcassa et al., "Fluorescence spectroscopy applied to orange trees," Laser Phys., vol. 16, no. 5, pp. 884-888, May 2006.

[6] J. Belasque Jr., M. C. G. Gasparoto, and L. G. Marcassa, "Detection of mechanical and disease stresses in citrus plants by fluorescence spectroscopy," Appl. Opt., vol. 47, no. 11, pp. 1922-1926, Apr. 2008

[7] M. A. Cho et al., "Potential utility of the spectral red-edge region of SumbandilaSat imagery for assessing indigenous forest structure and health," Int. J. Appl. Earth Observ. Geoinformation, vol. 16, pp. 85-93, Jan. 2012.

[8] E. R. Hunt et al., "A visible band index for remote sensing leaf chlorophyll content at the canopy scale," Int. J. Appl. Earth Observ. Geoinformation, vol. 21, pp. 103-112, Apr. 2013.

[9] Z. Oumar, O. Mutanga, and R. Ismail, "Predicting thaumastocoris peregrinus damage using narrow band normalized indices and hyperspectral indices using field spectra resampled to the hyperion sensor," Int. J. Appl. Earth Observ. Geoinformation, vol. 21, pp. 113-121, Apr. 2013.

[10] P. K. Palacharla et al., "A hyperspectral reflectance data based model inversion methodology to detect reniform nematodes in cotton," in Proc. IEEE Trento Workshop Analysis Multi-Temporal Remote Sens. Images, Jul. 2011, pp. 249-252.

[11] D. Ashourloo et al., "Developing an Index for Detection and Identification of disease stages," IEEE Geosci. Remote Sens. Lett., vol. 13, no. 6, pp. 851-855, Jun. 2016.

[12] L. Wang et al., "A study on the changes of pinus massoniana spatial pattern by pine wood nematode invasion based on remote sensing and GIS," in Proc. IEEE Int. Symp. Geosci. Remote Sens., Jul. 2006, pp. 2697-2700.

[13] H. Z. M. Shafri and N. O. Hamdan, "Hyperspectral Imagery for mapping disease infection in oil palm plantation using vegetation indices and red edge technique," Amer. J. Appl. Sci., vol. 6, pp. 1031-1035, 2009.

[14] S. Hamzeh et al., "Estimating salinity stress in sugarcane fields with spaceborne hyperspectral vegetation indices," Int. J. Appl. Earth Observ. Geoinformation, vol. 21, pp. 282-290, Apr. 2013.

[15] J. R. Jensen, Remote Sensing of the Environment: An Earth Resource Perspective, 2nd ed. London, U.K.: Pearson, 2006. p. 672.

[16] F. E. Nicodemus, "Geometrical considerations and nomenclature for reflectance," National Bureau of Standards, US Department of Commerce, Washington, DC, USA, 1977

[17] K. Anderson, J. L. Dugan, and A. Macarthur, "On the reproducibility of field-measured reflectance factors in the context of vegetation studies," Remote Sens. Environ., vol. 115, no. 8, pp. 1893-1905, Aug. 2011

[18] Spectral Response Curves of the RapidEye Sensor, 2012. [Online]. Available:https://resa.blackbridge.com/files/2014/06/Spectral_Response_Curv es.pdf.

[19] A. Stein et al. Spatial Statistics for Remote Sensing. Norwell, MA, USA: Kluwer, 1999, p. 284.

[20] J. W. Rouse, "Monitoring vegetation systems in the great plains with ERTS," in Proc. Third ERTS Symp., NASA SP-351, NASA, Washington, DC, USA, 1973, vol. 1, pp. 309-317.

[21] D. Haboudane et al., "Integrated narrow-band vegetation indices for prediction of crop chlorophyll content for application to precision agriculture," Remote Sens. Environ., vol. 81, pp. 416-426, 2002.

[22] J. Liu et al., "Estimating crop stresses, aboveground dry biomass and yield of corn using multi-temporal optical data combined with a radiation use efficiency model," Remote Sens. Environ., vol. 114, no. 6, pp. 1167-1177, Jun. 2010.

[23] S. M. Adler-Golden et al., "Atmospheric correction for short-wave spectral imagery based on MODTRAN4," Proc. SPIE, vol. 3753, 1999.

[24] ENVI, "Atmospheric correction module: QUAC and FLAASH User's Guide," ITT Visual Information Solutions, 2009.
[25] G. W. Felde, G. P. P. Anderson, S. M. Adler-Golden, N. W. Matthew, and A. Berk, "Analysis of hyperion data with the FLAASH atmospheric correction algorithm," in Proc. Int. Geosci. Remote Sens. Symp., Toulouse, France, 2003, pp. 90-92

[26] R. G. Congalton and K. Green, Assessing the Accuracy of Remotely Sensed Data: Principles and Practices. Boca Raton, FL, USA: Lewis Publishers, p. 137, 1999.

[27] K. Usha and B. Singh, "Potential applications of remote sensing in horticulture-A review," Scientia Horticulturae, vol. 153, pp. 71-83, Apr. 2013.

[28] L. Perin et al., "Diazotrophic Burkholderia species associated with fieldgrown maize and sugarcane," Appl. Environ. Microbio., vol. 72, pp. $3103-$ 3110, 2006.

[29] M. Zhang et al, "Detection of stress in tomatoes induced by late blight disease in California, USA, using hyperspectral remote sensing," Int. J. Appl. Earth Observ. Geoinformation, vol. 4, no. 4, pp. 295-310, Nov. 2003

[30] A. Apan, A. Held, S. Phinn, and J. Markley, "Detection of sugarcane 'orange rust' disease using EO-1 Hyperion hyperspectral imagery," Int J.Remote Sens., vol. 25, pp. 489-498, 2004.

[31] S. Adelabu et al., "Evaluating the impact of red-edge band from rapideye image for classifying insect defoliation levels," ISPRS J. Photogrammetry Remote Sens., vol. 95, pp. 34-41, 2014.

[32] G. S. Abawi and J. Cheno, Concomitant Pathogen and Pest Interactions. Plant and Nematode Interaction, Madison, WI, USA: Amer. Soc. Agronomy, 1998, pp. 135-158.

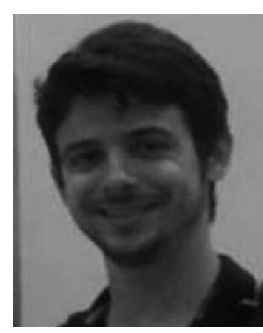

George Deroco Martins received the Graduate degree in cartographic engineering and the M.S. and Ph.D. degrees in cartografic sciences from São Paulo State University, Presidente Prudente, Brazil, in 2010, 2013, and 2016, respectively.

$\mathrm{He}$ is currently an Adjunct I Professor of the Federal University of Uberlândia, Monte Carmelo, Brazil. He has experience in remote sensing of vegetation and topography of structures and mines.

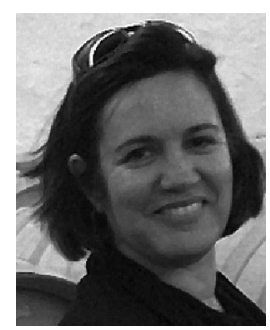

Maria de Lourdes Bueno Trindade Galo received the Graduate degree in forestry engineering from the Federal University of Viçosa, Minas Gerais, Brazil, in 1981. She received the M.S. degree in remote sensing from the National Institute for Space Research, São José dos Campos, São Paulo, Brazil, in 1988 and the $\mathrm{Ph}$.D. degree in environmental engineering sciences from the University of São Paulo, São Carlos, Brazil, in 2000 .

She is currently an Assistant Professor in the School of Technology and Sciences, São Paulo State University, Presidente Prudente, Brazil. She has experience in geoscience and remote sensing with an emphasis on the inference and modeling of physical and environmental processes.

Dr. B. T. Galo is a Fellow FP2 of the National Scientific and Technological Development Council (CNPq).

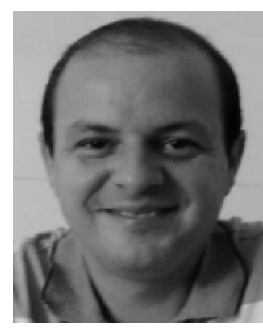

Bruno Sérgio Vieira received the Graduate degree in agronomy and the M.S. and Ph.D. degrees in phytopathology from the Federal University of Viçosa, Viçosa, Brazil, in 2002, 2004, and 2008, respectively.

$\mathrm{He}$ is currently an Adjunct III Professor of the Federal University of Uberlândia, Monte Carmelo, Brazil. He has experience in the field of agronomy, with emphasis in phytopathology, working mainly in the following areas: fungal taxonomy, diagnosis of plant diseases, nematology, biological control of weeds with phytopathogenic fungi, and biological control of plant diseases. He has been an Advisor to the Rectory at Monte Carmelo Campus since February 2017. 